Article

\title{
Optimization of the Production of 1,1-Diethoxybutane by Simulated Moving Bed Reactor
}

\author{
Jasper Spitters, Jonathan C. Gonçalves $\left(\mathbb{D}\right.$, Rui P. V. Faria * ${ }^{\mathbb{D}}$ and Alírio E. Rodrigues
}

check for

updates

Citation: Spitters, J.; Gonçalves, J.C.; Faria, R.P.V.; Rodrigues, A.E. Optimization of the Production of 1,1-Diethoxybutane by Simulated Moving Bed Reactor. Processes 2021, 9 , 189. https://doi.org/10.3390/ pr9020189

Received: 30 November 2020

Accepted: 13 January 2021

Published: 20 January 202

Publisher's Note: MDPI stays neutral with regard to jurisdictional claims in published maps and institutional affiliations.

Copyright: (c) 2021 by the authors. Licensee MDPI, Basel, Switzerland. This article is an open access article distributed under the terms and conditions of the Creative Commons Attribution (CC BY) license (https:// creativecommons.org/licenses/by/ $4.0 /)$.
Laboratory of Separation and Reaction Engineering-Laboratory of Catalysis and Materials (LSRE-LCM), Department of Chemical Engineering, Faculty of Engineering, University of Porto, Rua Dr. Roberto Frias s/n, 4200-465 Porto, Portugal; up201811199@fe.up.pt (J.S.); jcgs@fe.up.pt (J.C.G.); arodrig@fe.up.pt (A.E.R.)

* Correspondence: ruifaria@fe.up.pt; Tel.: +351-22-508-14-00

\begin{abstract}
Simulated moving bed technology is applied in the field of pharmaceutical, petrochemical and fine chemistry. It shows capability in separating multicomponent mixtures up to high purities. In this work, an attempt was made to optimize the production of 1,1-diethoxybutane (DEB), using the simulated moving bed technology. A fixed bed model is made with good agreement with experimental results. This fixed bed model was expanded to a simulated moving bed model. This model was used to determine the optimum conditions regarding the switching time and flowrates in each section. From this model, the optimum switching time was found to be $2.4 \mathrm{~min}$, and the ratio of liquid flowrate over the solid flowrate in Section 1 to Section 4 of the SMBR was found to be $4.24,1.77,3.03$ and 1.35 , respectively. Under those conditions, the productivity was $19.8 \mathrm{~kg}$ DEB per liter of adsorbent per day, and the desorbent consumption was $6.1 \mathrm{~L}$ of ethanol per $\mathrm{kg}$ of DEB. The results were obtained with a minimum purity of the extract and raffinate of $97 \%$.
\end{abstract}

Keywords: 1,1-diethoxybutane; heterogeneous catalysts; adsorption; process intensification; simulated moving bed reactor

\section{Introduction}

One of the most relevant environmental issues is global warming due to the increase of $\mathrm{CO}_{2}$ in the atmosphere. Combustion of fossil fuels accounts for $82 \%$ of the increase of $\mathrm{CO}_{2}$ concentration [1]; therefore, a lot of research is focused on finding alternative fuels. The interest is even further increased due to the predicted shortage of fossil fuel reserves.

A form of these alternative fuels are biofuels such as bio alcohols and biodiesel. Nowadays, bioethanol is the most employed bio alcohol and it can be used in car engines pure or as a blend. Bioethanol is suitable for this use due to the high octane number and the high heat of vaporization [2].

Another biofuel is a biodiesel consisting of methyl esters or ethyl esters of long chain fatty acids. These are produced via a transesterification between an alcohol and vegetable oils [3]. The use of biodiesel instead of petroleum diesel is attractive, due to the renewable nature and lower toxicity, and because it produces no sulphur, no net $\mathrm{CO}_{2}$ and releases less hydrocarbons and non-gaseous emissions [4]. However, biodiesel has some drawbacks, namely high particles and NOx emissions [5]. Additionally, petroleum diesel has better properties regarding oxidization stability, energy content and operability at low temperatures [6]. A promising method to overcome these drawbacks is the blending of biodiesel with other compounds like acetals. The use of 1,1-diethoxyethane has shown promising results, but the flashpoint is below the European regulation limit [7]. Therefore, the use of acetals with higher molecular weights is an interesting option. In this context, 1,1-diethoxybutane (DEB) has been identified as a potential alternative additive.

Acetals are produced via the reaction of two molecules of a monohydric alcohol and an aldehyde catalyzed by an acid. The reaction is shown in Figure 1. 


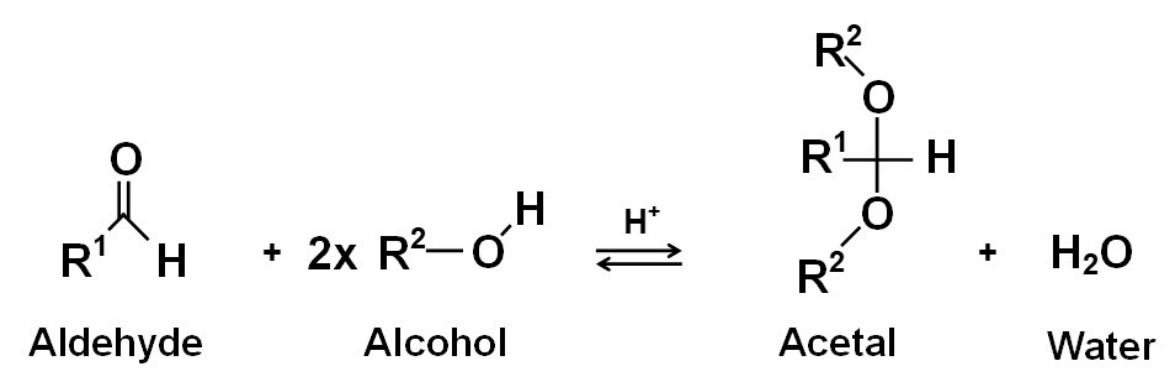

Figure 1. Overall acetalization reaction scheme.

The most optimal way to perform this reaction is via a heterogeneous catalyst, due to the separation difficulties and possible miscibility issues of a homogenous catalyst [8-10]. Ion-exchange resins have been reported as one of the most suitable types of catalysts for the acetalization reaction. For the particular case of the synthesis of DEB, the use of Amberlyst47 as catalyst has been proposed and deeply studied by different research groups due to its fast kinetics and to the negligible amounts of by-products formed in its presence [11,12].

Because of the equilibrium limitations of this reaction, normal batch operation results in low conversion. Therefore, the implementation of Process Intensification strategies, as the simultaneous separation of one of the products during the reaction, seems a good option to enhance the conversion. The open literature reports reactive distillation [13] and membrane reactors [14] as potential multifunctional reactors for the synthesis of DEB. In all cases, the removal of water from the reaction media was the key step to increase the conversion.

The synthesis of this acetal by reactive distillation, by membrane reactors or by more or less complex combinations of reaction, pervaporation and distillation units has been thoroughly studied over the last decade [13-15]; however, despite the economic potential demonstrated by some of these processes, the performance of both conventional and multifunctional reactors was rather limited. For instance, the reported limiting reactant conversion for reactive distillation units was always below 50\% [13], while for membrane reactors, the limiting reactant conversion was typically comprised between $40 \%$ and $80 \%[14,16]$. These values are higher than those attained in conventional reactors operated under similar conditions but are quite low for these types of multifunctional reactors and reactive systems. The exothermic character of the DEB synthesis acetalization reaction and the relatively high temperatures at which reactive distillation and membrane reactor processes typically operate (above $343 \mathrm{~K}$ ) lead to considerable thermodynamic limitations since at higher temperatures the equilibrium conversion will be lower.

A less energy intensive alternative way to accomplish this is by using the principle of chromatography. Chromatography is a process where two components can be separated based on affinity with a solid phase. The two components are carried via a solvent through a solid phase. The component with less affinity to the solid phase will move faster compared to the component with more affinity. This principle can be applied in this case, where water is the more retained component and 1,1-diethoxybutane (DEB) is the less retained component with ethanol as solvent. As previously mentioned, Amberlyst- 47 has shown good properties regarding enhancing the reaction [11]. Amberlyst-47 will act as a catalyst, as well as the adsorbent of water.

The acetalization reaction can be carried out in a fixed bed, where Amberlyst-47 is packed in a column, and a mixture of ethanol and butanal will flow through [17]. The disadvantage of this is that the process can only be carried out in batch mode, and after a certain time, the process needs to be stopped because the catalyst/adsorbent will be saturated. From this point on, water will be present in the product and the process has to be stopped; the catalyst/adsorbent has to be cleaned so the process can be restarted. This is very time consuming, implies the use of large amounts of regeneration solvent, and thus this is not a viable option. Therefore, a true moving bed reactor (TMBR) was investigated, where in a column the solid phase is pumped around in a counter-current 
operation. The column has two inlet streams, namely, the feed and the desorbent, and two outlet streams, namely, the extract and raffinate. The column can be divided in four sections. In Section 1, the recycled liquid and the fresh desorbent enter the column at one end. In this section, the solid phase is cleaned by the liquid flow, so the solid leaving the column is saturated in the desorbent and can be recycled to Section 4. In Section 2, the desorption of the less-absorbed component takes place, to prevent the extract from being contaminated by this component, together with the chemical reaction. In Section 3, the chemical reaction proceeds and the adsorption of the more-adsorbed component take place to prevent the raffinate from being contaminated with this component. In Section 4, the solid recycle enters the column at one end, and the liquid is cleaned so that the liquid leaving the column can be recycled to Section 1. In Figure 2, a schematic representation of a true moving bed is shown.

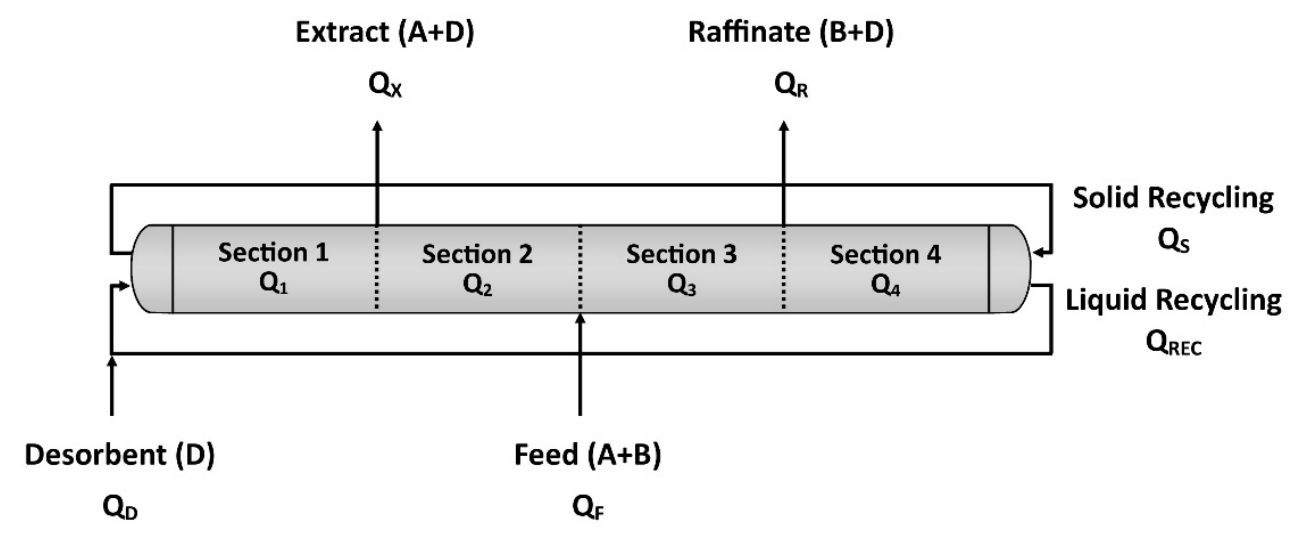

Figure 2. Schematic representation of a true moving bed.

The TMBR operating mode would enable continuous operation; however, moving the solid phase around presents many mechanical difficulties, which makes the process not viable. Therefore, the simulated moving bed (SMB) was invented. In this process, the movement of the solid phase is simulated by changing the input and output locations of all the streams. A schematic review is shown in Figure 3.

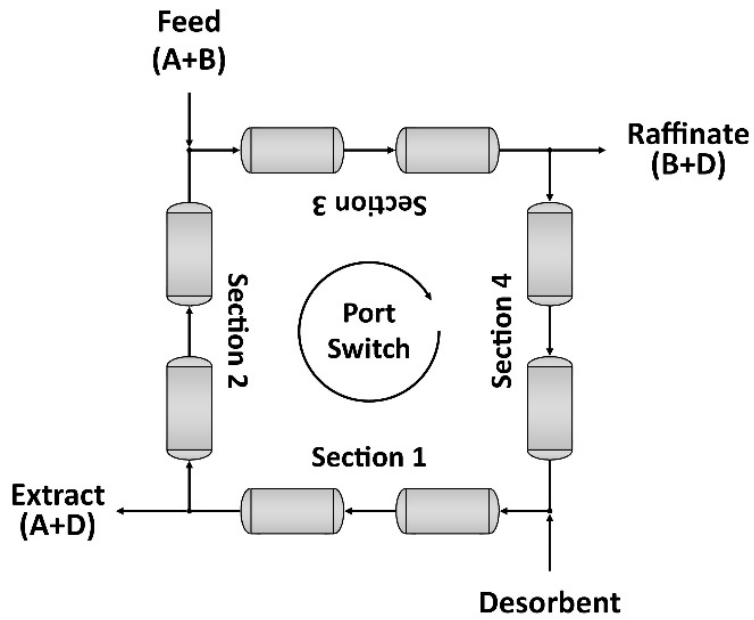

(D)

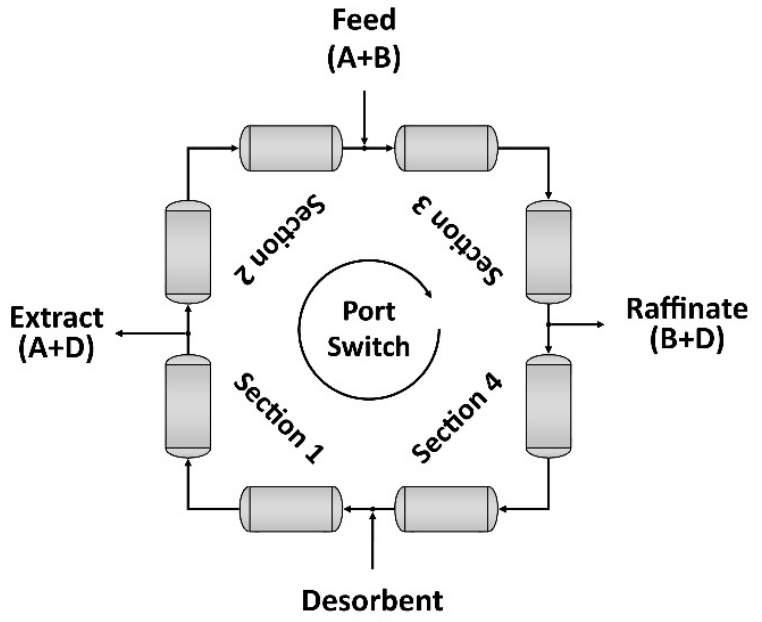

(D)

Figure 3. Simulated moving bed process.

In Figure 3, a process of eight identical columns is represented, where each two columns represent one section. These sections have the same function as in the TMBR. In this case, every section has the same number of columns, and a 2-2-2-2 configuration is 
used; however, in some cases it can be more efficient to have more columns, for example, in Sections 2 and 3, and use a 1-3-3-1 configuration. After a certain time, designated switching time, all the inlet and outlet ports are shifted by one column, in the same direction as the liquid flow. This simulates the movement of the solid flow, while the solid flow is stationary. Because of the switching, there is no real steady state, but only a cyclic steady state. When this state is achieved, the concentration profile that is observed in eight consecutive switches will be exactly the same (for an eight-column unit presented as example). The cyclic steady state is achieved after a short number of cycles (typically 10-30 cycles). After eight switches, the inlet and outlet ports are at the same place again, and the whole cycle starts again. Therefore, it is called a cyclic steady state because the unit internal concentration profiles and outlet concentration histories are cyclically the same from that moment on.

The SMB separation principle can be applied to the multifunctional reactors concept and include the reaction in a so-called simulated moving bed reactor (SMBR). In fact, this technology has been implemented for the production of fuel additives [18] and has been demonstrated to be particularly effective for the synthesis of acetals [19-21]. For the synthesis of DEB, Amberlyst- 47 will be used as stationary phase (catalyst and adsorbent) and ethanol is used as desorbent. This has the advantage of shifting the reaction equilibrium to the preferred side of the reaction, and almost all the butanal will react. The raffinate will contain ethanol and DEB, where the extract will contain ethanol and water. Ethanol from both of these streams can be separated and recycled back to the unit in order to reduce the overall SMBR desorbent consumption.

In this work, the synthesis of DEB by SMBR will be studied and optimized. A mathematical model will be developed and validated against experimental data obtained from the open literature [22], which will then be used for this purpose. A two-level SMBR optimization procedure will be adopted [23], based on the Separation Volumes concept [24,25], together with a sensitivity analysis of some of the most relevant operating parameters.

\section{Methods}

\subsection{Mathematical Model}

In order to model an SMBR, a fixed bed column has to be modelled and validated. The thermodynamic properties and validation data are based on previous work [22] In this model, the assumption of constant packing and bed length is made. For each compound, a second-order partial differential equation is set up for the concentration in the bulk, an ordinary differential equation for the average concentration inside the particle, and an algebraic equation for the adsorbed concentration in equilibrium with the average concentration inside the particle pores. The mass balance for the bulk phase for component $i$ is presented in Equation (1).

$$
\frac{\partial C_{i}}{\partial t}+\frac{\partial\left(u C_{i}\right)}{\partial z}+\frac{(1-\varepsilon)}{\varepsilon} \frac{3}{r_{p}} K_{L, i}\left(C_{i}-\bar{C}_{p, i}\right)=D_{a x} \frac{\partial}{\partial z}\left(C_{T} \frac{\partial x_{i}}{\partial z}\right)
$$

The particle mass balance for component $i$ is presented in Equation (2).

$$
\frac{3}{r_{p}} K_{L, i}\left(C_{i}-\bar{C}_{p, i}\right)=\varepsilon_{p} \frac{\partial \bar{C}_{p, i}}{\partial t}+(1-\varepsilon) \frac{\partial q_{i}}{\partial t}-v_{i} \frac{\rho_{b}}{1-\varepsilon} r\left(\bar{C}_{p, i}\right)
$$

where $q i$ is the concentration of component $i$ in the solid. With the following boundary conditions in Equations (1)-(3),

$$
\begin{array}{rr}
t=0 & C i=\bar{C}_{p, i}=C_{0} \\
z=0 & u C_{i}-\left.D_{a x} C_{T} \frac{\partial X_{i}}{\partial z}\right|_{z=0}=u C_{i, F}
\end{array}
$$




$$
z=\left.L \quad \frac{\partial C_{i}}{\partial z}\right|_{z=L}=0
$$

where $C_{0}$ refers to pure eluent concentration, which means there is only ethanol present. In the equations, $u$ refers to the interstitial velocity, $K_{L}$ is the global mass transfer coefficient, $D_{a x}$ is the axial dispersion coefficient, $t$ is the time variable, $z$ is the axial coordinate, $v_{i}$ is the stoichiometric coefficient, $\rho_{b}$ is the bulk density and $r\left(\bar{C}_{p, i}\right)$ is the reaction rate based on the average particle concentration. The reaction rate is shown in Equation (6),

$$
r=k_{c} \frac{a_{E t O H} a_{B} \frac{a_{W} a_{D E B}}{K_{e q} a_{E t O H}}}{\left(1+K_{s, W} a_{W}\right)^{2}}
$$

where $a_{i}$ corresponds to the activity coefficient. These coefficients are based on the average particle concentration and are calculated via the universal quasichemical functional-group activity coefficient (UNIFAC) method. The equilibrium constant $K_{e q}$, the water equilibrium constant $K_{S, D}$ and the reaction kinetic constant $k_{\mathcal{c}}$ were determined in a previous study [11] and are represented by Equations (7)-(9).

$$
\begin{aligned}
K_{e q} & =7.73 * 10^{-2} \exp \left(\frac{1036.8}{T(K)}\right) \\
K_{S, D} & =1.454 * 10^{-4} \exp \left(\frac{2920.68}{T(K)}\right) \\
K_{C} & =3.21 * 10^{5} \exp \left(\frac{-4561.06}{T(K)}\right)
\end{aligned}
$$

To describe the adsorption equilibrium, the multicomponent Langmuir isotherm was considered and is shown in Equation (10).

$$
q_{i}=\frac{Q_{i} K_{i} \bar{C}_{p, i}}{1+\sum_{j=1}^{n} K_{j} \bar{C}_{p, j}}
$$

In this equation, $Q_{i}$ represents the total molar capacity for each component per volume of adsorbent and $K_{i}$ represents the equilibrium constant for each component. These values, determined in a previous work [22], are presented in Table 1.

Table 1. Multicomponent Langmuir isotherm parameters for the species involved in the synthesis of 1,1-diethoxybutane (DEB) at $303 \mathrm{~K}$ [22].

\begin{tabular}{ccc}
\hline Component & $Q\left(\mathbf{m o l ~ L}_{\text {Solid }}{ }^{-1}\right)$ & $K\left(\mathbf{L ~ m o l}^{-\mathbf{1}}\right)$ \\
\hline Ethanol & 10.58 & 7.24 \\
Butanal & 3.08 & 0.12 \\
Water & 34.47 & 8.18 \\
DEB & 3.59 & 0.06 \\
\hline
\end{tabular}

For the model to be accurate, the interstitial velocity variation has to be accounted for and is calculated via the total mass balance assuming ideal additivity. This is represented by Equation (11).

$$
\frac{d u}{d z}=-\frac{(1-\varepsilon)}{\varepsilon} \frac{3}{r_{p}} \sum_{i=1}^{N C} K_{L, i} V_{m o l, i}\left(C_{i}-\bar{C}_{p, i}\right)
$$

where $V_{m o l}$ is the molar volume of component $I$, with the following boundary condition:

$$
z=0 \quad u=Q_{i n} /(A * \varepsilon)
$$


where $A$ is the cross-sectional area, $\varepsilon$ is the porosity of the bed and $Q_{i n}$ and $Q_{o u t}$ represents the volumetric flow in and the volumetric flow out, respectively, in $l / s$.

The axial dispersion coefficient was based on an experimentally determined Péclet number. The Péclet number relates the ratio between convection and diffusion, and is shown in Equation (13).

$$
P e=\frac{L_{c} u}{D_{a x}}
$$

The assumption of a global mass transfer has been made, where the internal and external mass transfer are combined into one coefficient. The coefficient is defined in Equation (14).

$$
\frac{1}{K_{L}}=\frac{1}{K_{e}}+\frac{1}{\varepsilon_{p} K_{i}}
$$

To determine the internal mass transfer, an approximation for the average value was used in Equation (15).

$$
K_{i}=\frac{5 \frac{\varepsilon_{p} D_{m}}{\tau}}{r_{p}}
$$

where $\tau$ represents the tortuosity factor which was set to 2 by experimental data fitting.

The external mass transfer coefficient was approximated via the Wilson and Geankpolis relation, shown in Equation (16).

$$
S h_{p}=\frac{1.09}{\varepsilon}\left(R e_{p} S c\right)^{0.33} 0.0015<R e<55
$$

In Equation (16), $S h_{p}, R e_{p}$ and $S c$ are, respectively, the particle Sherwood number, the particle Reynolds number and the Schmidt number, which are determined via Equations (17)-(19).

$$
\begin{aligned}
S h_{p} & =\frac{K_{e} d_{p}}{D_{m}} \\
R e_{p} & =\frac{\rho d_{p} u}{\eta} \\
S c & =\frac{\eta}{\rho D_{m}}
\end{aligned}
$$

The infinite dilution diffusivities are estimated by the Scheibel correlation in Equation (20).

$$
D_{A, B}^{0}=\frac{8.2 * 10^{-8} T}{\eta_{b} V_{M o l, A}^{\frac{1}{3}}}\left(1+\left(\frac{3 V_{M o l, B}}{V_{M o l, A}}\right)^{\frac{1}{3}}\right)
$$

In which $D_{A, B}^{0}$ is the diffusion coefficient for a dilute $A$ in solvent $B$. Since we have a multicomponent system, the Perkins and Geankopolis mixing rule is applied, as shown in Equation (21).

$$
D_{A, m} \eta_{m}^{0.8}=\sum_{i=1}^{n} x_{i} D_{A, i}^{0} \eta_{i}^{0.8}
$$

Since the infinite dilution diffusivity is only valid for low concentrations, the mixture diffusivity of ethanol cannot be calculated in this way. Since ethanol is used as the solvent, it will always be present in high concentrations, so for ethanol the mixture diffusivity is approximated by the self-diffusion coefficient. The self-diffusion is calculated via Equation (22), based on a previous work. [26].

$$
\frac{D_{A A} \eta_{A}}{k_{B} T}=\frac{1}{2 \pi}\left(\frac{\widetilde{N}_{A}}{\check{V}_{A}}\right)^{\frac{1}{3}}
$$


In which $D_{A A}$ represents the self-diffusion coefficient, $K_{B}$ represents the Boltzmann constant, $\widetilde{N}_{A}$ represents the Avogadro number and $\breve{V}_{A}$ represents the molar volume. The results are in the same order of magnitude as those reported in other studies [27].

As seen in Equation (21), the mixture viscosity is used to determine the mixture diffusivity. The mixture viscosity is determined using the Gruenberg-Nissan correlation, shown in Equation (23).

$$
\ln \left(\eta_{m}\right)=\sum_{i} x_{i} \ln \left(\eta_{i}\right)
$$

For the SMBR, the balances for the nodes are given in Equations (24)-(27). For the extract, the balance is:

$$
C_{i I I, \text { in }}=C_{i I, \text { out }}
$$

For the raffinate:

$$
C_{i I V, \text { in }}=C_{\text {iIIIout }}
$$

For the eluent:

$$
C_{i I, i n}=\frac{u_{I V}}{u_{I}} C_{i I V, o u t}+\frac{u_{D}}{u_{I}} C_{i}^{D}
$$

For the feed:

$$
C_{i I I I, \text { in }}=\frac{u_{I I}}{u_{I I I}} C_{i I I, o u t}+\frac{u_{F}}{u_{I I I}} C_{i}^{F}
$$

\subsection{Performance Parameters}

To optimize the process, the performance parameters need to be determined. Since there is no steady state, the performance parameters are based on average concentrations in the raffinate and extract streams. The raffinate purity is determined via Equation (28).

$$
P U R=\frac{C_{D E B, R}}{C_{B, R}+C_{W, R}+C_{D E B, R}}
$$

where the concentrations represent the average concentrations of butanal, water and ethanol in the raffinate within a cycle.

The extract purity is determined via Equation (29).

$$
P U X=\frac{C_{W, X}}{C_{B, X}+C_{W, X}+C_{D E B, X}}
$$

where the concentrations represent the average concentrations of butanal, water and ethanol in the extract within a cycle. The purity values resulting from the equations indicate the purity obtained after removing the ethanol, as commonly considered for this type of process. When ethanol is included in the equation, the purity is much lower.

The butanal conversion is determined via Equation (30).

$$
X=\left(1-\frac{Q_{x} C_{B, X}+Q_{R} C_{B, R}}{Q_{F} C_{B, F}}\right)
$$

where $Q_{x}$ represents the extract flowrate, $Q_{R}$ the raffinate flowrate, $Q_{F}$ the feed flowrate and $C_{B, F}$ the butanal concentration in the feed.

The DEB productivity is determined via Equation (31).

$$
P R=\frac{Q_{R} C_{D E B, R}}{(1-\varepsilon) V_{\text {unit }}}
$$

where $C_{D, R}$ represents the DEB concentration in the raffinate stream and $V_{\text {unit }}$ represents the volume of all the columns. 
The desorbent consumption is determined via Equation (32).

$$
D C=\frac{\left(Q_{D} C_{E t O H, D}+Q_{F}\left(C_{E t O H, F}-2 X C_{B, F}\right) V_{m o l, E t O H}\right)}{P R(1-\varepsilon) V_{\text {unit }}}
$$

where $Q_{D}$ represents the flowrate of the eluent going into the SMBR and $V_{m o l, A}$ represents the molar volume of ethanol.

\subsection{Numerical Solution}

The model was written in gPROMS (general PROcess Modeling System). The axial coordinate was discretized using a second-order centered finite difference method (CFDM). The discretization results in a system of ordinary differential equations integrated over time using the DASOLV integrator implementation in gPROMS.

\section{Results and Discussion}

In this section, the results regarding the fixed bed adsorptive reactor model validation and the optimization results attained through the extrapolation of the previously validated single column model to the multicolumn SMBR unit will be presented.

\subsection{Fixed Bed Adsorptive Reactor Model Validation}

In order to optimize the SMBR, the model of a single fixed bed has to be validated with experimental data. The experimental data were obtained from a previous work [22]. Three different experiments were compared, namely: a breakthrough curve of water with ethanol, a breakthrough curve of DEB with ethanol and a reaction experiment. The experimental conditions used are presented in Table 2.

Table 2. Experimental conditions used for the fixed bed simulations.

\begin{tabular}{cccc}
\hline Experiment & 1 & 2 & 3 \\
Bed length $(\mathrm{cm})$ & 10.95 & 11.18 & 11.1 \\
Column diameter & 2.6 & 2.6 & 2.6 \\
$(\mathrm{~cm})$ & 303 & 303 & 303 \\
Temperature $(\mathrm{K})$ & 0.42 & 0.42 & 0.42 \\
Bed porosity & 0.5 & 0.5 & 0.5 \\
Particle porosity & 64.4 & 64.4 & 64.4 \\
Péclet number & 5.1 & 7.59 & 7 \\
Flowrate $\left(\mathrm{mL} \mathrm{min}^{-1}\right)$ & 0.579 & 0 & 16.958 \\
$C_{0, \text { ethanol }}(\mathrm{mol} / \mathrm{L})$ & 0 & 55.26 & 0 \\
$C_{0, \text { water }}(\mathrm{mol} / \mathrm{L})$ & 5.535 & 0 & 0 \\
$C_{0, \text { DEB }}(\mathrm{mol} / \mathrm{L})$ & 16.958 & 16.897 & 11.4 \\
$C_{F, \text { thanol }}(\mathrm{mol} / \mathrm{L})$ & 0 & 0.212 & 3.61 \\
$C_{F, \text { water }}(\mathrm{mol} / \mathrm{L})$ & 0.001 & 0 & 0 \\
$C_{F, D E B}(\mathrm{~mol} / \mathrm{L})$ & & &
\end{tabular}

For these experiments, the concentration at the outlet of the bed is registered, these are the outlet concentrations. The model and the experimental results are plotted from Figures 4-6. 




Figure 4. Breakthrough curve between ethanol and DEB experimental conditions provided in Table 2 for experiment 1 [22].

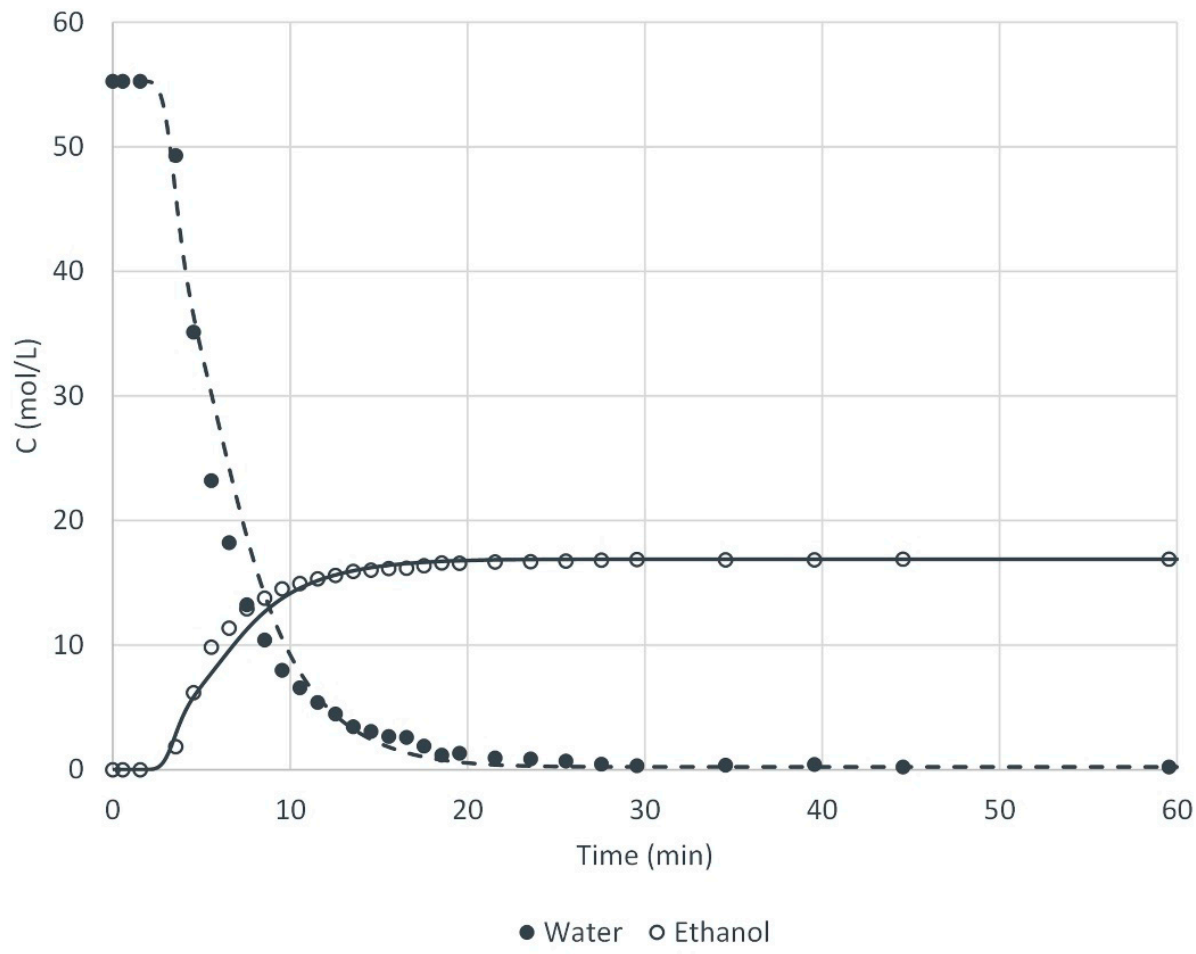

Figure 5. Breakthrough curve between ethanol and water experimental conditions provided in Table 2 for experiment 2 [22]. 


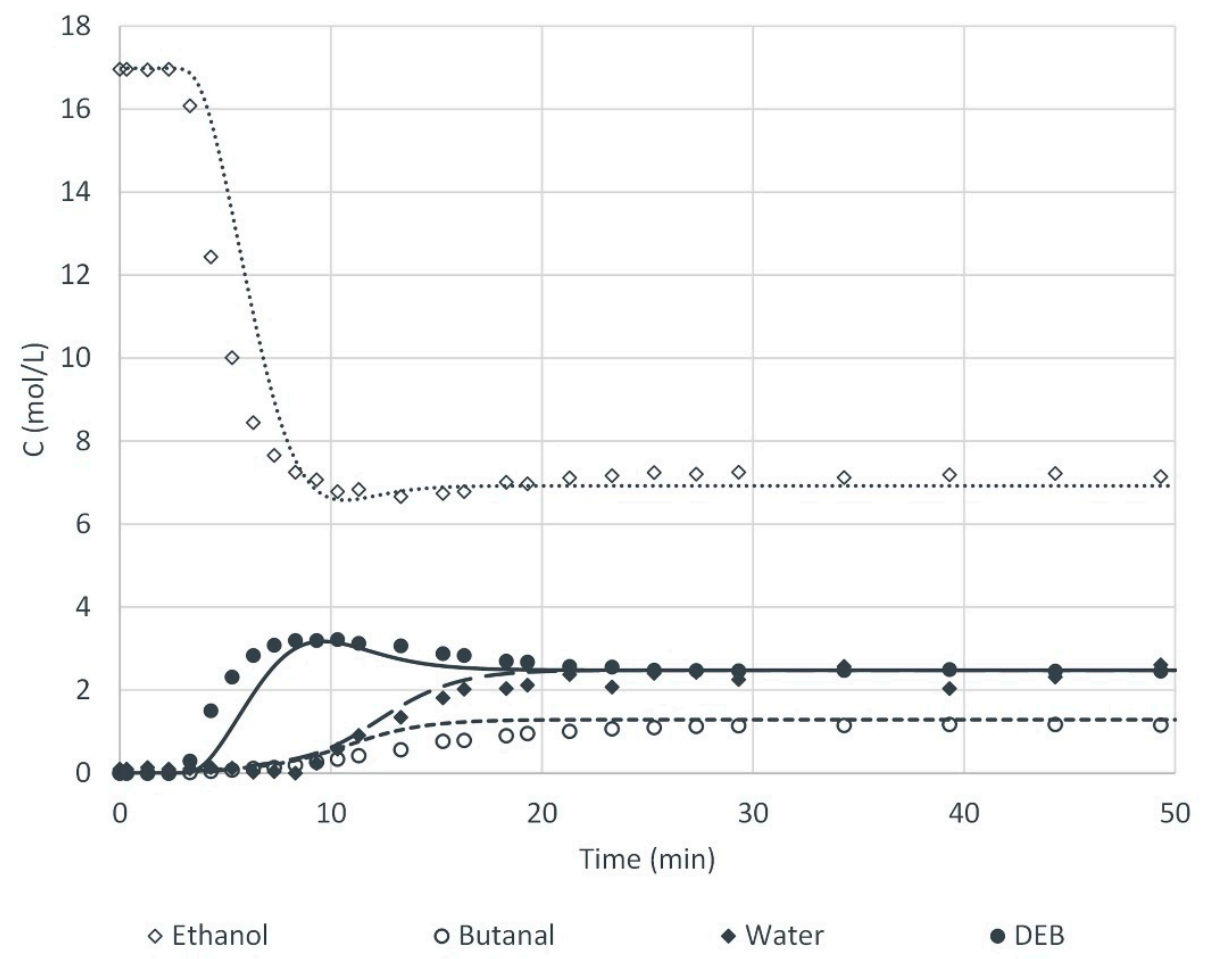

Figure 6. Reaction breakthrough curve experimental conditions provided in Table 2 for experiment 3 [22].

It can be seen from these plots that there is good agreement between the model results and the experimental results. To quantify this agreement, Equation (33) is used to determine the correlation factor.

$$
R_{\text {Correl }}^{2}=1-\left(\frac{\sum_{i=1}^{N C} \sum_{j=1}^{N E} \sum_{k=1}^{N P}\left(C_{\text {out }, i, j, k}^{\text {exp }}-C_{\text {out }, i, j, k}^{\text {mod }}\right)^{2}}{\sum_{i=1}^{N C} \sum_{j=1}^{N E} \sum_{k=1}^{N P}\left(C_{\text {out }, i, j, k}^{\text {exp }}-\bar{C}_{\text {out }, i, j, k}^{\text {mod }}\right)^{2}}\right)
$$

The correlation factor is calculated for all of the three breakthrough experiments using values from the model described in this work, and the values from [22]. The biggest difference between the two models is the way the diffusion coefficient of ethanol is determined. In this model, it is determined using the self-diffusion coefficient, which is more suitable considering the high concentrations of ethanol present throughout the system. This should represent the phenomena more accurately compared to when it is computed via the infinite dilution diffusivity.

From Table 3 it can be concluded that the fixed bed model fairly represents the experiments. The lower values in the reaction, compared to the binary curves, are mainly caused by the deviation in the ethanol and DEB curves within the first $500 \mathrm{~s}$. This deviation has a major impact on the correlation factor but it was already observed in the results attained by Graça et al. [22], being slightly improved in this work through the modifications made in the estimation of ethanol diffusion coefficient.

Table 3. Correlation factors attained for the breakthrough curves used for the fixed bed reactor model validation.

\begin{tabular}{ccc}
\hline & This Work & Previous Work [22] \\
\hline Ethanol and Water & 0.991 & 0.989 \\
Ethanol and Deb & 0.998 & 0.999 \\
Reaction & 0.954 & 0.949 \\
\hline
\end{tabular}




\subsection{Sensitivity Analysis to the SMBR Operating Parameters}

In order to guarantee that the cyclic steady state was reached every time, the same simulation was run for 12, 20 and 40 cycles. No differences could be observed between 20 and 40 cycles' separation regions. Some were observed between 12 and 20 cycles, albeit quite small. Hence, it was decided to use 20 cycles, in order to be sure that in every scenario, the cyclic steady state was reached. In Table 4 the experimental conditions are presented.

Table 4. Simulated moving bed reactor (SMBR) conditions.

\begin{tabular}{cc}
\hline Parameter & Value \\
\hline Temperature $(\mathrm{K})$ & 303 \\
Configuration & $3-3-3-3$ \\
Column Length $(\mathrm{cm})$ & 23.0 \\
Column diameter $(\mathrm{cm})$ & 2.6 \\
Bed porosity & 0.42 \\
Particle porosity & 0.5 \\
Péclet number & 64.4 \\
Ethanol feed concentration (mol/L) & 12.266 \\
Butanal feed concentration (mol/L) & 3.064 \\
\hline
\end{tabular}

In Figure 7, the history of the purity of the raffinate and the extract stream are plotted against the number of cycles. It can be seen that 20 cycles are enough in order for the system to reach the cyclic steady state.

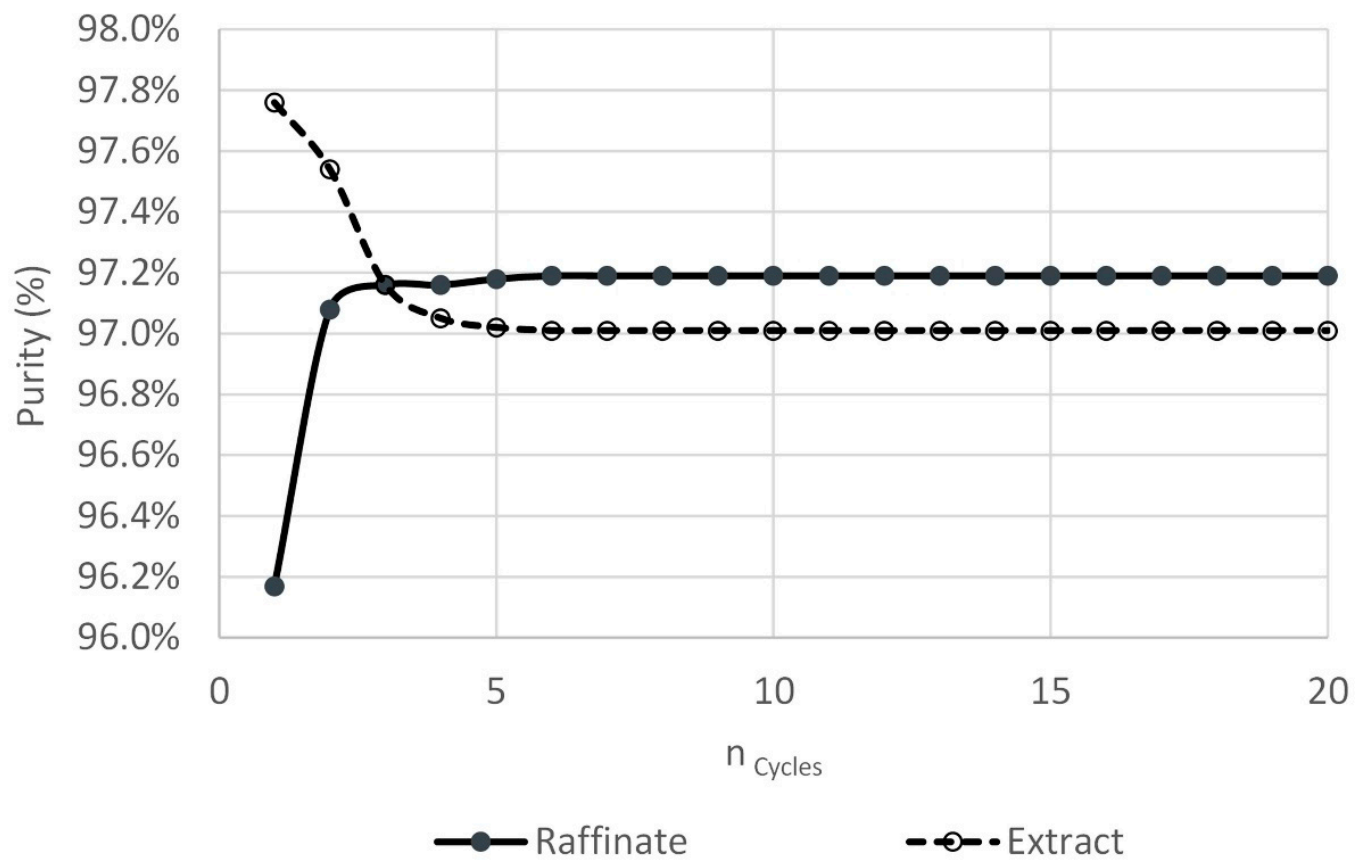

Figure 7. Outlet streams' purity histories over the number of cycles.

Now that the fixed bed model is validated, the SMBR can be modelled. In the SMBR, one of the most important parameters is the $\gamma$ value. This parameter represents the velocity of the liquid over the flow rate of the solid, in each section from 1 to 4 . The equation for the gamma value is presented in Equation (34).

$$
\gamma_{j}=\frac{u_{j}}{u_{s}}
$$


where the solid flow in an SMB is represented by Equation (35).

$$
u_{s}=\frac{L_{c}}{t_{\text {switch }}}
$$

The main function of Sections 1 and 4 is to clean the solid and the desorbent, respectively, as stated above. In this section, the optimal switching time will be determined. For this, the value of $\gamma_{1}$ and $\gamma_{4}$ should be a set value, to ensure that at all times the desorbent and solvent are cleaned properly. This is called a sensitivity analysis, because the influence of the switching time on the performance parameters is determined. These values are determined via Equations (36) and (37),

$$
\begin{gathered}
\gamma_{1 \text { min }}=\frac{(1-\varepsilon)}{\varepsilon}\left(\varepsilon_{p}+\left(1-\varepsilon_{p}\right) \frac{q_{W, 1}}{\bar{C}_{p, W, 1}}\right) \\
\gamma_{4 \max }=\frac{(1-\varepsilon)}{\varepsilon}\left(\varepsilon_{p}+\left(1-\varepsilon_{p}\right) \frac{q_{\mathrm{DEB}, 1}}{\overline{\mathrm{C}}_{p, \mathrm{DEB}, 1}}\right)
\end{gathered}
$$

with a safety factor included, which is set to $20 \%$. If the system is working properly, in Sections 1 and 4, only ethanol should be present, so in the isotherm, the denominator is only represented by the contribution of ethanol. However, Equations (36) and (37) are only valid for TMBR. Because the solid is not really moving in the SMBR, the relative liquid velocity to the solid is represented by Equation (38).

$$
u_{L}=u_{L}^{*}+u_{s}^{*}
$$

In this equation, the * refers to the flow in the TMBR. If this Equation is divided by the solid flow rate, the ratio between the liquid flow rate and the solid flow rate appears on the left-hand side of the equation. In that case, it can be seen that the $\gamma$ value in SMBR is equal to the gamma value of a TMBR plus 1 . So, to determine $\gamma_{1}$ and $\gamma_{4}$, a value of 1 must be added to Equations (36) and (37). This results in a value of 3.465 and 1.635 for $\gamma_{1}$ and $\gamma_{4}$, respectively. When these values are used, Sections 1 and 4 work properly, and the desorbent and solid are cleaned completely. For the rest of the simulations in this section, these values should be maintained. This means that the recycle flow rate and the eluent flow rate are set for each specific switching time value. The $\gamma_{2}$ and $\gamma_{3}$ values need to be determined regarding a purity requirement of the extract and the raffinate. The ratios in Sections 2 and 3 can be changed by altering the feed flowrate and the extract flowrate. From these flowrates, the raffinate flowrate is calculated by closing the mass balance.

When the purity requirement is set, a region within the $\gamma_{2}-\gamma_{3}$ plane that satisfies the purity requirement is delimited. This is called the separation region in the case of SMB and reactive-separation region in the case of SMBR. In Figure 8 an idealized situation of the separation region is shown.

In Figure 8, the triangle (formed by the vertexes $\mathrm{a}, \mathrm{b}$ and $\mathrm{w}$ ) is the separation region. Within that region, the raffinate and extract satisfy the purity requirements. The real separation region will not be a perfect triangle as the one in this figure, because of nonidealities in the process, due to mass transfer, for example. Even though it will not be a triangle, it will have a tip, which is the point furthest away from the diagonal. From an economical point of view, this is the most interesting point to operate, because the productivity is the highest, and the desorbent consumption is the lowest. However, at this point, one of the purities is at the limit of the purity requirement. Therefore, to ensure that the desired purity is attained, regardless of the possible flowrate fluctuations when operating real SMBR units, the operating point should be slightly closer to the diagonal. 


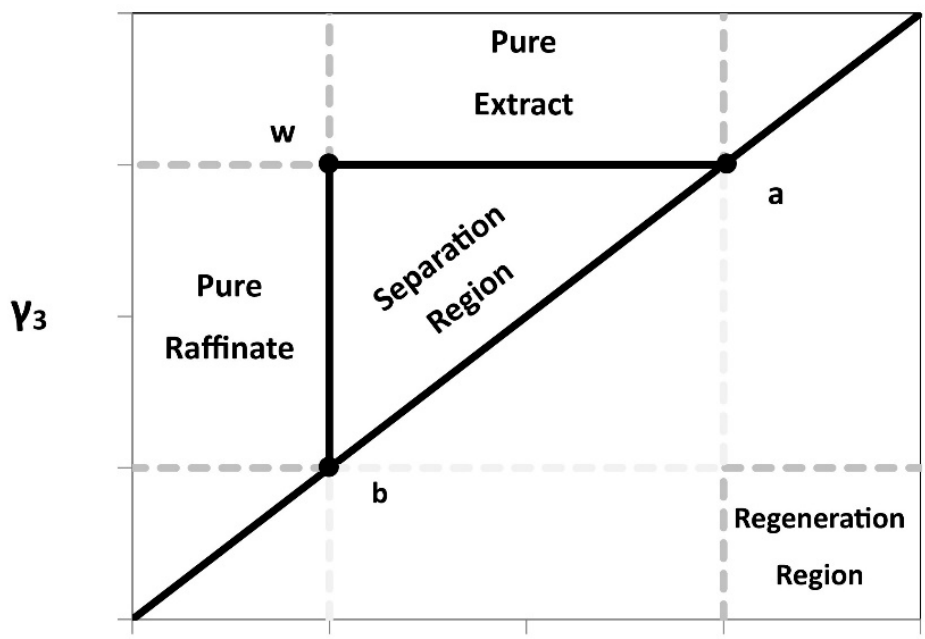

\section{$\gamma_{2}$}

Figure 8. Separation region for linear isotherms assuming the equilibrium theory is valid.

To determine this reactive-separation region, multiple simulations are run with different flow rates. Because the $\gamma_{1}$ and $\gamma_{4}$ are set, the recycle and eluent flow are also set. The simulations are run until the cyclic steady state is reached, and then the raffinate and extract purities are known. At the beginning of the simulation, the extract and feed flowrates are set, and the raffinate flowrate is calculated, in order to close the mass balance. At the first simulation, a low value should be set to the feed flow and extract flow. This way, both $\gamma_{2}$ and $\gamma_{3}$ values are high, and should be outside the reactive-separation region. The next simulation should have a higher extract flowrate with the same feed flowrate. This way, the point on the graph moves parallel to the diagonal. At a certain extract flowrate, the point gets inside of the separation region, and at some point, with an even higher extract flow rate, the point gets outside the region. At this moment, the boundaries of the reactive-separation region are known, with a certain feed flowrate. The next point is with the same extract flowrate that is just outside the region, but with a higher feed flowrate. Increasing the feed flowrate moves the point perpendicular to the diagonal. Because it is known that at best, the reactive-separation region is a triangle, as presented in Figure 8, this point should still be outside of the region. Now the extract flowrate is decreased, and will move inside the region, and eventually get outside of the region again. From that point, the feed flowrate is increased, and after that, the extract flowrate will be increased again. This goes on until a certain point where the purity requirements will not be met anymore by changing the extract flowrate. From that moment, the maximum feed flowrate is reached, corresponding to the vertex of the region. At this moment, the separation region can be drawn (with several discrete points corresponding to simulations with different $\gamma$ and switching time values combinations that ran until the cyclic steady state was reached), and the performance parameters of the vertex will be compared with other vertexes, obtained using different switching times, in a first approach. It has to be noted that conversion is an important factor, but since the conversion is computed regarding butanal (the limiting reactant), and the desorbent is ethanol, the conversion will almost go to completion in all the cases.

As was stated before, the separation region will not be a perfect triangle. But since we are not interested in constructing the whole separation region for every simulation, it is only done once, while in the remaining situations only the points closer to the vertex of the reactive-separation region were simulated to reduce the computation time. In Figure 9 the reactive-separation region is shown with a switching time of $4.5 \mathrm{~min}$. The reactiveseparation region was drawn by setting a purity requirement of $97 \%$ for both raffinate and extract. 




Figure 9. Separation region using a switching time of $4.5 \mathrm{~min}$ and a $20 \%$ safety factor for $\gamma_{1}$ and $\gamma_{4}$.

From Figure 9, it can be observed that the separation region is not an ideal triangle, but it still has a vertex, which represents the optimal operating point for this switching time. Changing the switching time will change the separation region regarding the $\gamma_{2}$ and $\gamma_{3}$ values, but the shape will be similar. The main thing that will change is its area, because a more appropriate switching time will result in a larger separation region. The conditions used for the simulation are presented in Table 4 . For the further simulations that are done in this work, these conditions were maintained.

In Figure 10, the productivity and desorbent consumption are plotted against the switching time. Every point on this graph represents the productivity and the desorbent consumption corresponding to the vertex of the reactive-separation region attained for that particular switching time.

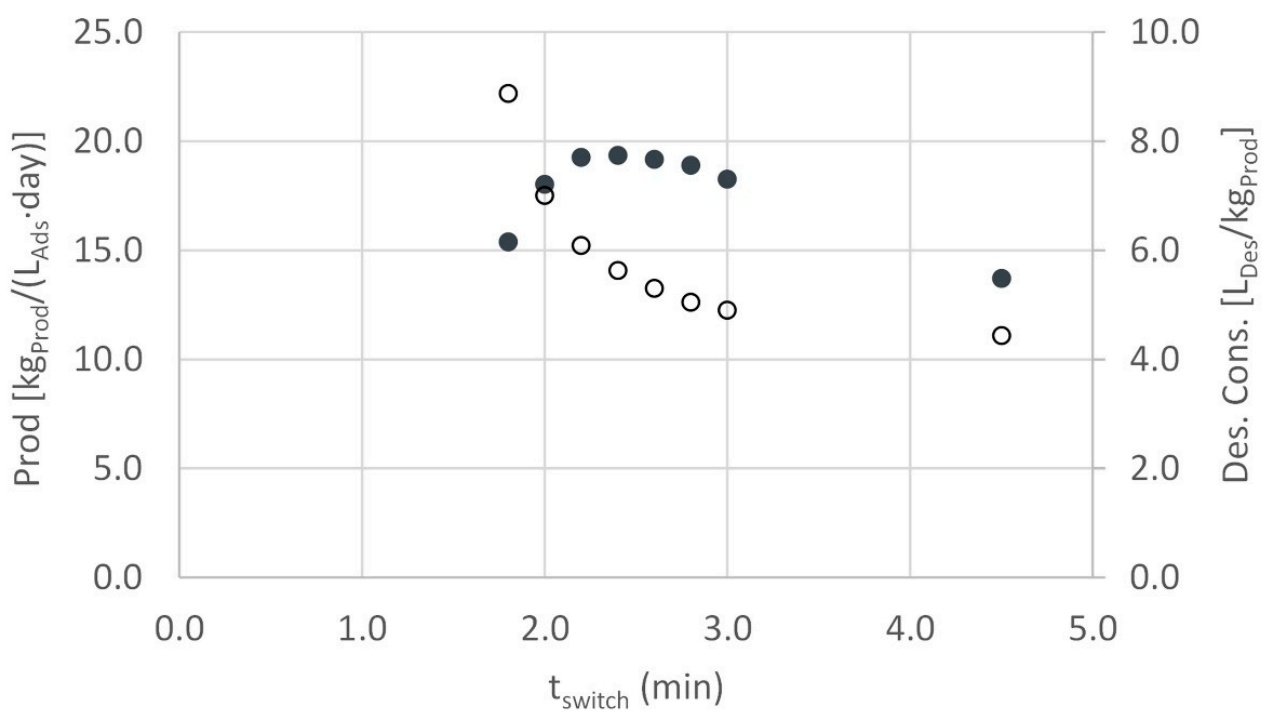

- Prod [kgA/(LAds·day)] o Des. Cons. [LDes/kgProd]

Figure 10. Sensitivity analysis regarding the influence of switching time on the productivity and the desorbent consumption, by setting a $20 \%$ safety factor for $\gamma_{1}$ and $\gamma_{4}$. 
From Figure 10, a maximum is observed regarding the productivity at a switching time of $2.4 \mathrm{~min}$. If the switching time is further decreased, in order to have enough contact time between the reactants and the catalyst, the feed flowrate has to be lower. When the switching time is further increased, the contact time becomes longer than needed, so this reduces the efficiency of the process, and so it reduces the productivity, as well. From this, it can be concluded that a switching time of $2.4 \mathrm{~min}$ is the optimum.

\subsection{Optimization of DEB Synthesis by SMBR: Separation Volumes}

In the sensitivity analysis performed in the previous section, where the operating performances were determined for multiple switching times, the values of $\gamma_{1}$ and $\gamma_{4}$ were kept constant, considering a $20 \%$ safety factor relatively to the values provided by the Equilibrium Theory (Equations (34) and (35)). The optimization procedure that will be implemented in this section will allow the maximization of the productivity and the minimization of the desorbent consumption through the optimization of $\gamma_{2}$ and $\gamma_{3}$ values as a function of $\gamma_{1}$ and $\gamma_{4}$, defining a minimum purity requirement of $97 \%$.

The two-level SMBR optimization procedure was adopted was based on the Separation Volumes concept $[24,25]$. This methodology (previously used in the optimization of SMB separations [28]) can be interpreted as an extrapolation of the Reactive-Separation Regions methodology, commonly used of the determination of the optimum flow rate ratios in Sections 2 and 3 of the SMBR (for predetermined $\gamma_{1}, \gamma_{4}$ and switching time values), coupled with a sensitivity analysis to the flow rate ratios in Sections 1 and 4 . The limit values for the latter variables can be determined through the Equilibrium Theory, as explained earlier, which defines the maximum eluent recycling flow rate in Section 4 and the minimum desorbent flow rate in Section 1, which allow the regeneration of the liquid and solid phases, respectively. Therefore, in the Reactive Separation Volumes methodology, several reactive-separation regions are determined for different combinations of $\gamma_{1}$ and $\gamma_{4}$ values, sequentially approaching the limit values imposed by the Equilibrium Theory to these variables. The procedure to determine each of these reactive-separation regions is described in detail in the previous section and basically consists of determining the $\left(\gamma_{2}, \gamma_{3}\right)$ sets that meet the target species purity specifications for each $\left(\gamma_{1}, \gamma_{4}\right)$ set. Repeating the process for different $\left(\gamma_{1}, \gamma_{4}\right)$ combinations, as detailed before, will allow the determination of the reactive separation volumes.

The optimization process can then be divided into two levels: the first is the optimization of the productivity or, in other words, the maximization of the difference $\left(\gamma_{3}-\gamma_{2}\right)$, since this corresponds to the highest feed flow rate that the unit can treat; and the second is the optimization of the desorbent consumption, which corresponds to the minimum $\left(\gamma_{1}-\gamma_{4}\right)$, since the desorbent flow rate will decrease as this difference decreases. At the end of this procedure, the optimum flow rates are known for the predetermined optimum switching time (which is $2.4 \mathrm{~min}$, according to the results reported in the previous section).

In Figures 11 and 12, two 3D plots are presented, where the desorbent consumption and the productivity are plotted against the values of $\gamma_{1}$ and $\gamma_{4}$.

From these plots, it can be seen that the optimum productivity is reached with a $\gamma_{1}$ value of 4.24 and a $\gamma_{4}$ of 1.35. From the plot with the desorbent consumption it can be seen that this point is not the optimum point, but the optimum point regarding the desorbent consumption corresponds to a significantly lower productivity. Since ethanol is used as a desorbent and this is a widely available bulk chemical, the optimum point is chosen regarding the highest productivity. At this point a productivity of $19.8 \mathrm{~kg}$ DEB per liter of adsorbent per day, a desorbent consumption of $6.1 \mathrm{~L}$ of ethanol per $\mathrm{kg}$ of DEB is reached.

Using this optimum point, the internal concentration profile is plotted in Figure 13. 




Figure 11. Productivity performance against $\gamma_{1}$ and $\gamma_{4}$ at the optimum $\gamma_{2}$ and $\gamma_{3}$.

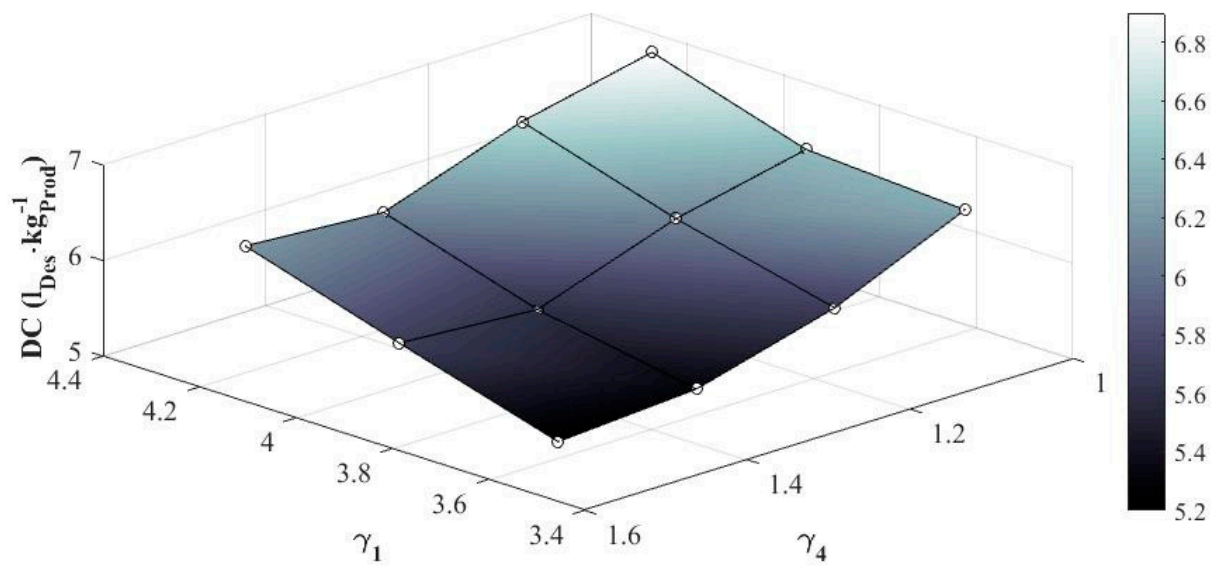

Figure 12. Desorbent consumption performance against $\gamma_{1}$ and $\gamma_{4}$ at the optimum $\gamma_{2}$ and $\gamma_{3}$.

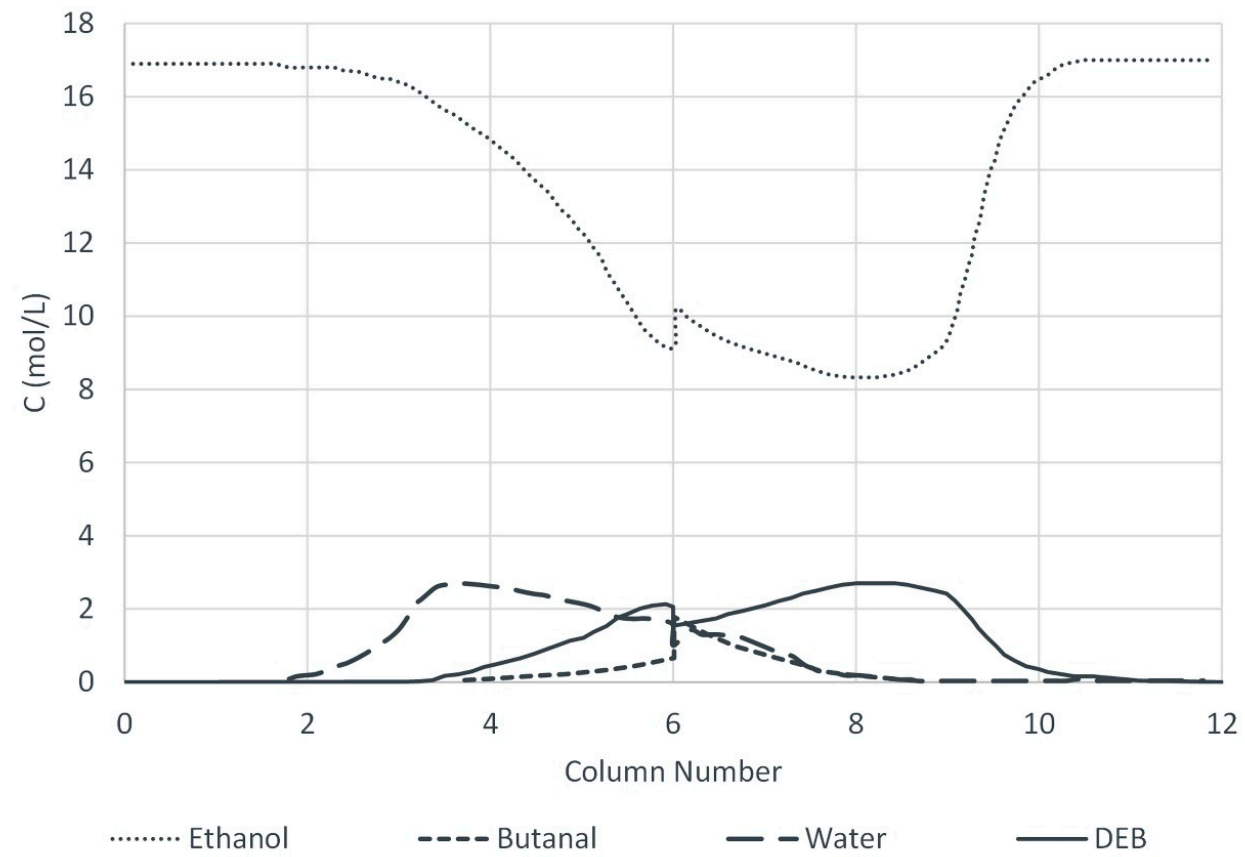

Figure 13. Cyclic steady state profile at half switching time. 
In Figure 13, the concentrations are taken at half the switching time, during the last cycle. In this figure, the $\mathrm{x}$-axis divides the graph into four sections, which correspond to the four sections mentioned earlier. It is important to see that at the extract port at column 3 , almost no DEB should be present, since this would decrease the purity of the extract. The same goes for the raffinate port at column 9, where no water should be present. From Figure 13 it is also clear that the purity does not include the ethanol, which comprises a high fraction of both outgoing streams.

The limiting reactant conversion value attained for the SMBR process optimized within this work was $99.99 \%$. Hence, the multifunctional reactor proposed and studied in this work clearly outperforms reactive distillation units $[12,13]$ and membrane reactors $[14,16]$ previously reported in the open literature, in terms of reactants conversion. The main reason for the high conversion values attained in the SMBR is related to its operating conditions, more specifically, its operating temperature. Since the acetalization reaction between ethanol and butanol is exothermic, the chemical reaction thermodynamic equilibrium will benefit from lower operating temperatures, which will lead to higher equilibrium conversions. As the SMBR unit studied in this work operates at $303 \mathrm{~K}$, the chemical reaction thermodynamic limitations are less penalizing in terms of the overall process performance than those observed for reactive distillation units and membrane reactors which typically operate above $343 \mathrm{~K}$. Moreover, the products' separation by adsorption, which is also an exothermic phenomenon, is simultaneously favored by lower operating temperatures. These facts are at the foundation of the SMBR-enhanced performance. Furthermore, lower operating temperatures may also represent a considerable advantage in terms of the overall energy consumption of the process.

As stated in previous studies [15], the main cost of the DEB consists of the raw material costs. Therefore, it is important to use the ethanol and butanal as efficiently as possible. Since ethanol is used as desorbent in the SMBR, butanal almost reaches full conversion. So, butanal is used as efficiently as possible. In both the raffinate and extract streams, the products are diluted in ethanol, so this can be recycled in order to optimize the process. The ethanol in the extract stream can be purified using a hydrophilic membrane. This method does not have issues with azeotropes compared to distillation, and has shown its capabilities in previous studies [29]. This way, the ethanol can be used as desorbent again. From the raffinate stream, the DEB needs to be separated from the ethanol. This can be achieved using distillation, since the boiling point of ethanol is at $78^{\circ} \mathrm{C}$ and the boiling point of DEB is at $143^{\circ} \mathrm{C}$.

\section{Conclusions}

The production of 1,1-diethoxybutane using the simulated moving bed reactor technology was investigated, using ethanol and butanal as starting materials.

The simulated moving bed reactor model used in this work was based on a single column fixed bed model developed in a previous work. This model was validated against experimental data showing good agreement with the experimental results.

A two-level optimization procedure based on the Separation Volumes concept was successfully implemented to this case study. The optimum ratios between the liquid flow rate over the solid flow rate in Sections 1-4 were found to be 4.24, 1.77, 3.03 and 1.35 , respectively, for a switching time of $2.4 \mathrm{~min}$. Using these results, a productivity of $19.8 \mathrm{~kg}$ 1,1-diethoxybutane per liter of adsorbent per day and a desorbent consumption of $6.1 \mathrm{~L}$ of ethanol per $\mathrm{kg}$ of 1,1-diethoxybutane were estimated for the simulated moving bed reactor, considering a minimum purity of the extract and raffinate of $97 \%$. Despite the promising performance demonstrated by the simulated moving bed reactor for the synthesis of 1,1-diethoxybutane, it must be noted that there are other variables that can affect the productivity and desorbent consumption that were not taken into account in this study. These include the configuration, feed concentration and the dimensions of the column. 
Reactive distillation units and membrane reactors have been reported in the open literature as the most efficient multifunctional reactors for the synthesis of 1,1-diethoxybutane; however, the results attained for the simulated moving bed reactor in this work revealed that adsorption-based reactive processes can outperform the technologies previously proposed for the synthesis of this acetal. Since this process involves a thermodynamically limited exothermic reaction, it will take advantage from the lower operating temperatures typically associated with chromatographic separations (due to the exothermic nature of the adsorption). The simulated moving bed reactor can reach complete limiting reactants conversion at $303 \mathrm{~K}$, while the remaining state-of-the-art technologies typically do not overcome $50 \%$ to $70 \%$, because their operating temperature is above $343 \mathrm{~K}$.

Author Contributions: A.E.R. conceptualized and coordinated all the aspects of the work, R.P.V.F. developed the gPROMS mathematical models used in the work and defined the optimization strategy adopted, J.S. performed all the simulations and prepared the original manuscript, J.C.G. revised the methodology and the results. All authors were involved in the review and editing of the final manuscript. All authors have read and agreed to the published version of the manuscript.

Funding: This work was financially supported by: Base Funding-UIDB/50020/2020 of the Associate Laboratory LSRE-LCM—funded by national funds through FCT/MCTES (PIDDAC).

Informed Consent Statement: Not applicable.

Data Availability Statement: The data presented in this study are available on request from the corresponding author.

Acknowledgments: The authors acknowledge FCT/MCTES (PIDDAC) for the financial support: Base Funding-UIDB/50020/2020 of the Associate Laboratory LSRE-LCM.

Conflicts of Interest: The authors declare no conflict of interest.

\section{Glossary}

$\begin{array}{ll}\text { List of symbols } & \\ a & \text { Activity } \\ A & \text { Cross-sectional area }\left(\mathrm{dm}^{2}\right) \\ C & \text { Concentration }\left(\mathrm{mol} \mathrm{L}^{-1}\right) \\ \mathrm{CO}_{2} & \text { Carbon dioxide } \\ C F D M & \text { Centered finite difference method } \\ D_{i, m} & \text { Diffusion coefficient of compound } i \text { in a mixture } \\ D_{a x} & \text { Axial dispersion coefficient } \\ D C & \text { Desorbent consumption }\left(\mathrm{L}_{\mathrm{des}} \mathrm{Kg}^{-1} \mathrm{DEB}\right) \\ D E B & 1,1 \text {-diethoxybutane } \\ k_{B} & \text { Boltzmann constant }\left(1.38064852 \times 10^{-23} \mathrm{~m}^{2} \mathrm{~kg} \mathrm{~s}^{-2} \mathrm{~K}^{-1}\right) \\ K & \text { Adsorption equilibrium constant }\left(\mathrm{L} \mathrm{mol}^{-1}\right) \\ k_{C} & \text { Reaction kinetic constant }\left(\mathrm{mol} \mathrm{g}^{-1} \mathrm{~s}^{-1}\right) \\ K_{E} & \text { External mass transfer }\left(\mathrm{dm} \mathrm{s}^{-1}\right) \\ K_{e q} & \text { Equilibrium constant } \\ K_{i} & \text { Internal mass transfer }\left(\mathrm{dm} \mathrm{s}^{-1}\right) \\ K_{L} & \text { Overall mass transfer coefficient }\left(\mathrm{dm} \mathrm{s}^{-1}\right) \\ K_{S, D} & \text { Water adsorption constant } \\ L & \text { Length of the column }(\mathrm{dm}) \\ N O_{x} & \text { Nitrogen oxides } \\ P R & \text { Productivity }\left(\mathrm{Kg} \text { DEB } \mathrm{L}_{\mathrm{ads}}{ }^{-1} \text { day }^{-1}\right) \\ P U R & \text { Raffinate purity }(\%) \\ P U X & \text { Extract purity }(\%) \\ Q & \text { Flow rate }\left(\mathrm{L} \mathrm{s}{ }^{-1}\right) \\ q & \text { Particle solid concentration }\left(\mathrm{mol} \mathrm{L}^{-1}\right) \\ Q_{i} & \text { Molar Adsorption capacity of compound } i\left(\mathrm{~mol} \mathrm{~L}^{-1}\right) \\ r & \text { Reaction rate }\left(\mathrm{mol} \mathrm{g} \mathrm{g}^{-1} \mathrm{~s}^{-1}\right) \\ R e & \text { Reynolds number } \\ & \end{array}$




$\begin{array}{ll}\text { Sc } & \text { Schmidt number } \\ S h & \text { Sherwood number } \\ \text { SMBR } & \text { Simulated moving bed reactor } \\ T & \text { Temperature }(\mathrm{K}) \\ t & \text { Time (s) } \\ T M B R & \text { True moving bed reactor } \\ u & \text { Interstitial Velocity }\left(\mathrm{dm} \mathrm{s}^{-1}\right) \\ V_{\text {mol }} & \text { Molar volume }\left(\mathrm{dm}^{3} \mathrm{~mol}^{-1}\right) \\ X & \text { Conversion }(\%) \\ x & \text { Molar fraction } \\ z & \text { Dimensionless axial coordinate }\left(\mathrm{dm} \mathrm{s}^{-1}\right) \\ \text { Greek letters } & \\ \beta & \text { Safety factor } \\ \gamma & \text { Ratio between liquid and solid interstitial velocities } \\ \varepsilon & \text { Porosity (volume void volume bed } \\ \eta & \text { Viscosity }(\mathrm{cP}) \\ \rho & \text { Density (g L } \\ \tau & \text { Tortuosity } \\ \text { Subscripts } & \\ B & \text { Butanal } \\ D & \text { Desorbent } \\ E t O H & \text { Ethanol } \\ F & \text { Feed } \\ i & \text { Component } i \\ m & \text { Mixture } \\ p & \text { Particle } \\ R & \text { Raffinate } \\ R e c & \text { Recycle } \\ W & \text { Water } \\ X & \text { Extract } \\ & \end{array}$

\section{References}

1. EIA. Emissions of Greenhouse Gases in the United States; EIA: Washington, DC, USA, 2001-2002.

2. Claesson, K. Effects of Nutrients Supplementation on Fermentability of Lignocellulosic Hydrolysates under High Gravity Conditions; Chalmers University of Technology: Gothenburg, Sweden, 2012.

3. Ma, F.; Hanna, M.A. Biodiesel production: A review. Bioresour. Technol. 1999, 70, 1-15. [CrossRef]

4. Atabani, A.E.; Silitonga, A.S.; Badruddin, I.A.; Mahlia, T.M.I.; Masjuki, H.H.; Mekhilef, S. A comprehensive review on biodiesel as an alternative energy resource and its characteristics. Renew. Sustain. Energy Rev. 2012, 16, 2070-2093. [CrossRef]

5. McCormick, R.L.; Graboski, M.S.; Alleman, T.L.; Herring, A.M.; Tyson, K.S. Impact of biodiesel source material and chemical structure on emissions of criteria pollutants from a heavy-duty engine. Environ. Sci. Technol. 2001, 35, 1742-1747. [CrossRef] [PubMed]

6. Moser, B.R.; Erhan, S.Z. Branched chain derivatives of alkyl oleates: Tribological, rheological, oxidation, and low temperature properties. Fuel 2008, 87, 2253-2257. [CrossRef]

7. Frusteri, F.; Spadaroa, L.; Beatriceb, C.; Guido, C. Oxygenated additives production for diesel engine emission improvement. Chem. Eng. J. 2007, 134, 239-245. [CrossRef]

8. Kolah, A.K.; Asthana, N.S.; Vu, D.T.; Lira, C.T.; Miller, D.J. Reaction kinetics of the catalytic esterification of citric acid with ethanol. Ind. Eng. Chem. Res. 2007, 46, 3180-3187. [CrossRef]

9. Andrade, J.; Arntz, D.; Kraft, M.; Prescher, G. Method for Preparation of Acetals. U.S. Patent 45,799,79A, 1 April 1986.

10. Silva, V.M.; Rodrigues, A.E. Kinetic studies in a batch reactor using ion exchange resin catalysts for oxygenates production: Role of mass transfer mechanisms. Chem. Eng. Sci. 2006, 61, 316-331. [CrossRef]

11. Rahaman, M.; Graça, N.; Pereira, C.; Rodrigues, A.E. Thermodynamic and kinetic studies for synthesis of the acetal (1, 1-diethoxybutane) catalyzed by Amberlyst 47 ion-exchange resin. Chem. Eng. J. 2015, 264, 258-267. [CrossRef]

12. Agirre, I.; Barrio, V.L.; Güemez, B.; Cambra, J.F.; Arias, P.L. Bioenergy II: The development of a reactive distillation process for the production of 1, 1 diethoxy butane from bioalcohol: Kinetic study and simulation model. Int. J. Chem. React. Eng. 2010, 8. [CrossRef]

13. Agirre, I.; Barrio, V.L.; Güemez, B.; Cambra, J.F.; Arias, P.L. Catalytic reactive distillation process development for 1,1 diethoxy butane production from renewable sources. Bioresour. Technol. 2011, 102, 1289-1297. [CrossRef]

14. Agirre, I.; Güemez, M.B.; Motelica, A.; van Veen, H.M.; Vente, J.F.; Arias, P.L. The conceptual design of a continuous pervaporation membrane reactor for the production of 1,1-diethoxy butane. AIChE J. 2012, 58, 1862-1868. [CrossRef] 
15. Agirre, I.; Uemez, M.B.E.; Motelica, A.; van Veen, H. A techno-economic comparison of various process options for the production of 1,1-diethoxy butane. J. Chem. Technol. Biotechnol. 2012, 87, 943-954. [CrossRef]

16. Agirre, I.; Güemez, M.B.; van Veen, H.M.; Motelica, A.; Vente, J.F.; Arias, P.L. Acetalization reaction of ethanol with butyraldehyde coupled with pervaporation. Semi-batch pervaporation studies and resistance of HybSi®membranes to catalyst impacts. J. Membr. Sci. 2011, 371, 179-188. [CrossRef]

17. Regufe, M.J.; Faria, R.; Ribeiro, A.M.; Loureiro, J.M. Synthesis of the Biofuel Additive 1,1-Diethoxybutane in a Fixed-Bed Column with Amberlyst-15 Wet. Chem. Eng. Technol. 2016, 39, 1509-1518. [CrossRef]

18. Zhang, Z.; Hidajat, K.; Ray, A.K. Application of Simulated Countercurrent Moving-Bed Chromatographic Reactor for MTBE Synthesis. Ind. Eng. Chem. Res. 2001, 40, 5305-5316. [CrossRef]

19. Graça, N.S.; Pais, L.S.; Silva, V.M.T.M.; Rodrigues, A.E. Analysis of the synthesis of 1,1-dibutoxyethane in a simulated moving-bed adsorptive reactor. Chem. Eng. Process. Process Intensif. 2011, 50, 1214-1225. [CrossRef]

20. Silva, V.M.T.M.; Rodrigues, A.E. Novel process for diethylacetal synthesis. AIChE J. 2005, 51, 2752-2768. [CrossRef]

21. Pereira, C.S.M.; Gomes, P.S.; Gandi, G.K.; Silva, V.M.T.M.; Rodrigues, A.E. Multifunctional reactor for the synthesis of dimethylacetal. Ind. Eng. Chem. Res. 2008, 47, 3515-3524. [CrossRef]

22. Graça, N.S.; Delgado, A.E.; Constantino, D.S.; Pereira, C.S.; Rodrigues, A.E. Synthesis of a renewable oxygenated diesel additive in an adsorptive reactor. Energy Technol. 2014, 2, 839-850. [CrossRef]

23. Minceva, M.; Rodrigues, A.E. Two-level optimization of an existing SMB for p-xylene separation. Comput. Chem. Eng. 2005, 29, 2215-2228. [CrossRef]

24. Azevedo, D.C.S.; Rodrigues, A.E. Design of a simulated moving bed in the presence of mass-transfer resistances. AIChE J. 1999, 45, 956-966. [CrossRef]

25. Rodrigues, A.E.; Pereira, C.; Minceva, M.; Pais, L.S.; Ribeiro, A.M.; Ribeiro, A.; Silva, M.; Graça, N.; Santos, J.C. Simulated Moving Bed Technology: Principles, Design and Process Applications; Elsevier Science: Oxford, UK, 2015.

26. Shi, Q.; Gonçalves, J.C.; Ferreira, A.F.P.; Plaza, M.G.; Rodrigues, A.E. Xylene isomerization over Beta zeolites in liquid phase. Ind. Eng. Chem. Res. 2018, 57, 5568-5579. [CrossRef]

27. Guevara-Carrion, G.; Vrabec, J.; Hasse, H. Prediction of self-diffusion coefficient and shear viscosity of water and its binary mixtures with methanol and ethanol by molecular simulation. J. Chem. Phys. 2011, 134, 074508. [CrossRef] [PubMed]

28. Coelho, L.C.D.; Filho, N.M.L.; Faria, R.P.V.; Ferreira, A.F.P.; Ribeiro, A.M.; Rodrigues, A.E. Separation of tartronic and glyceric acids by simulated moving bed chromatography. J. Chromatogr. A 2018, 1563, 62-70. [CrossRef]

29. Gravelle, S.; Yoshida, H.; Joly, L.; Ybert, C.; Bocquet, L. Carbon membranes for efficient water-ethanol separation. J. Chem. Phys. 2016, 145, 124708. [CrossRef] 